\title{
Learning technologies and the lifelong learner: armament or disarmament?
}

\author{
Jane Seale \\ School of Occupational Therapy and Physiotherapy, University of Southampton, \\ email:jks @@soton.ac.uk
}

\begin{abstract}
Educators at all levels are under pressure to produce 'lifelong learners'. Their task is to 'arm' the student with knowledge and skills that will enable them to be creative and enterprising scholars. One possible way of arming the lifelong learner is through the use of learning technologies. Learning technologies can offer armament by widening access and participation and offering flexible delivery. This paper will use the results of two evaluation studies to explore the argument that learning technologies have the capacity to both arm and disarm students. Results from an evaluation of an email discussion list will be presented to highlight how the way a learning technology is used may arm a learner by giving them information but disarm them by promoting a lack of confidence and a low valuation of discussion. Results from an evaluation of a Microcosm application will be presented to highlight how the way a learning technology is used may arm a learner by helping them to apply knowledge but disarm them by placing restrictions on their selfdirected learning. These results will be discussed in order to argue that the 'disarmament' of students through the use of learning technologies may place obstacles in the way of lifelong learning.
\end{abstract}

\section{Introduction}

In a general context, lifelong learning appears to be about increasing access to education and supporting individual development. In the specific context of the United Kingdom, lifelong learning is about converting people to a culture of learning in order that the nation can produce creative, enterprising scholars (Blunkett, 1998). In both contexts, it is considered that learning needs to be a lifelong commitment, in order that individuals can fulfil their potential and improve themselves.

It is generally accepted that learning technologies can increase access to education through flexible delivery and innovative uses of open and distance learning (Porritt, 1997; Lovie, McLean and Newlands, 1998). An examination of learning technology literature reveals strong consensus that the kind of learning to which people should be converted is more than just 
knowledge acquisition. Huge emphasis is placed on critical thinking and reflection. For example, Hammond and Trip (1998) argue:

The computer is starting to be used not just as a delivery mechanism or surrogate calculator, but to encourage the learner to ask questions, explore and form active hypotheses, in short as a cognitive tool for learning, an augmenter of intelligent study. (p. 88)

While McLoughlin and Oliver (1998) see learning as a social, collaborative and conversational experience and therefore argue that:

The conversation requires reciprocity and mutual understanding and this is achieved through talk, discussion, and negotiation. Computer assisted learning can support interaction, dialogue, reflection and conversation if learning tasks are structured appropriately. (p. 13)

In considering the kind of learning that learning technologies should promote, the language used in the literature conjures up images of a 'battle' to 'equip' learners. For example Steeples, Unsworth, Bryson, Goodyear, Riding, Fowell, Levey and Duffy (1996) talk of how discursive technologies can be used to 'challenge conventional, didactic modes of education' (p. 78). Hammond and Tripp (1992) use the metaphor of a 'Trojan Horse' to describe how the computer is starting to be used in psychology education, while Grabinger, Dunlap and Duffield (1997) talk of how learners need to be involved in a 'continual process of retooling their knowledge and skill base' (p. 5). The use of leaming technologies may equip learners in a positive way, such as that described by Grabinger et al. Alternatively, the use of learning technologies may equip learners in a negative way. For example, Carswell (1998) talks of how students who are ill-prepared to use the World Wide Web may be burdened with the 'extra cognitive load of developing new strategies for accessing Internet-based material' (p. 77). In other words, instead of being armed and well-prepared for learning, students who use learning technologies may be disarmed and denied a rich learning experience.

In this paper, two case examples of the use of learning technologies with university students will be described. The battle imagery highlighted in the literature will be utilized in order to develop the argument that the way learning technologies are used may serve to either arm or disarm learners.

\section{Case example I: email discussion list}

An email discussion list was set up by the author to support a first-year module of behavioural sciences being taught in an Occupational Therapy and Physiotherapy degree course at Southampton University. In order to promote and instigate discussion, case studies, topical news items, questions and summaries of arguments were posted. In order to inform discussion and enable students to place the issues in a context, lecture notes (PowerPoint slides) and reference lists were also posted. There was an implicit assumption that the students would reflect on the information contained in the lecture notes and use these reflections to contribute to a group discussion. This assumption reflects a common portrayal of email as an ideal means of providing opportunities for group discussion, tutor-student interaction and collaborative working (McAteer, Tolmie, Duffy, and Corbett, 1997).

The email list was evaluated through the use of both a paper-based and email-based questionnaire. The paper-based questionnaire was distributed amongst all 130 first-year 
students in December 1997 and invited comments on teaching and learning support, including the email list. There was a 36 per cent response rate for this questionnaire. The email-based questionnaire included open questions about students' reasons for using the list, and more closed questions asking them to rate the learning experiences offered by the list from 1 (most valuable) to 5 (least valuable). There was a 15 per cent response rate for this questionnaire. Finally, usage statistics were collated from Majordomo, in order to assess numbers of subscriptions and postings to the list.

\section{Case example 2: the CAT Microcosm application}

Computer Applications in Therapy (CAT) is a Microcosm application, designed by the author to support a third-year option offered within the School of Occupational Therapy and Physiotherapy at Southampton University (Seale, 1997). The basic design of the package is that students first choose one patient/client history and then browse through the resource information in order to find out as much as they can about whether or not the client in the case history would benefit from using a computer. Students can enter and browse through the resource information at any level and in any order they wish. They can follow pre-determined links or create their own search strategies. The final outcome is that students can use the material in the resource information to write a report on whether and how they would use a computer with their chosen clients. The application uses case studies to encourage students to apply the knowledge they gained from the package and to think carefully about when and how they would use computers with clients. Case studies are a popular method for facilitating self-directed learning, particularly when using CAL. For example Kahn and Yip (1996), in considering the pedagogic principles of case-based CAL, argue for case-based reasoning (CBR) whereby a set of examples or cases is employed in a structured network. A CBR network therefore offers students opportunities to use previous examples or cases to solve fresh problems. The student is helped to acquire an expert model through free or structured browsing.

In order to evaluate the usefulness of the CAT Microcosm application a small evaluation study was conducted in February 1997. Seven lecturers and eight third-year students were offered a 90-minute workshop in which the package was explained and demonstrated with opportunity for 'unstructured hands-on play'. At the end of the workshop they were asked to complete an evaluation questionnaire that contained a number of statements regarding the presentation, content and educational use of CAT. Respondents were asked to state whether they strongly agreed (score of 5 ) or strongly disagreed (score of 1 ) with each statement. In addition to answering the opinion questions, the students were asked to list the advantages and disadvantages of using the application.

\section{Evidence for armament and disarmament}

The results from the evaluations of the email list and the CAT Microcosm application provide some evidence that students could potentially be both armed and disarmed by their use of these learning technologies. This evidence will now be presented in more detail.

\section{Armed by information}

The data from the evaluation of the email discussion list revealed strong evidence that students highly valued the opportunity to obtain information in the form of lecture notes. For example, 


\begin{tabular}{ll}
\hline Ranking Positions & Summary of student rankings \\
\hline Ist: Theory lecture notes & 9 out of II of respondents gave a rank of I (Mean=1.54) \\
2nd: Applied lecture notes & 8 out of II of respondents gave a rank of 2 (Mean=2.09) \\
3rd: Reference lists & 6 out of II of respondents gave a rank of 3 (Mean $=3.18)$ \\
4th: Tutor-posted questions & 3 out of II of respondents gave a rank of 4 (Mean $=4.09)$ \\
5th: Student responses to questions & 6 out of II of respondents gave a rank of $5($ Mean $=5.45)$ \\
6th: Student-posted questions & 6 out of II of respondents gave a rank of 6 (Mean $=6.09)$
\end{tabular}

Table 1: Student rankings of the facilities offered by the email discussion list in terms of being useful to learning

the students ranked the learning experience offered by the lecture notes and reference lists higher than they ranked the posted discussion questions and their responses (see Table 1).

Interestingly, the theory notes were ranked above the applied notes, and tutor-posted questions were ranked higher than student-posted questions. Some of the comments made by the students may help to further our understanding of why the information obtained from the lecture notes was valued so highly (see Table 2 ).

\begin{tabular}{ll}
\hline Information & $\begin{array}{l}\text { Reinforced personal notes from lecture. Allows you to pay more attention in class. You } \\
\text { know there is always a back up if you don't understand things. Enabled me not to worry } \\
\text { about writing every single word down. I looked up the lecture notes to compensate for my } \\
\text { notes, which were never comprehensive. }\end{array}$ \\
Confidence & $\begin{array}{l}\text { I sometimes feel I may lack confidence in answering some topics. I don't feel I have enough } \\
\text { knowledge base yet to answer the questions. Being unsure of some of the subject areas } \\
\text { and not having experience of relevant areas inhibited me. I didn't understand some of the } \\
\text { questions. }\end{array}$ \\
\hline
\end{tabular}

Table 2: Example evaluation comments for the email discussion list

\section{Disarmed by a low valuation of discussion}

The information in Table 1 indicates that students using the email discussion list valued obtaining information above discussing the information. Usage statistics from Majordomo support this. So for example, statistics concerning the response to discussion questions revealed very poor response and contribution levels. Of the eight debate issues posted to the list by the tutor, five failed to gain a single response by the students. Of the three issues that elicited a response, only two or three students responded.

\section{Armed with an opportunity to apply knowledge}

The data from the evaluation of the CAT Microcosm application revealed evidence that a major advantage of using the application was the ability to obtain information that can be applied to other learning situations such as modules and placements (see Table 3). Interestingly, the students have listed more opportunities for applying knowledge than the lecturers.

\section{Disarmed by a lack of confidence}

In trying to understand why the discussion element of the email list was not used or valued, the evidence suggests that some students appear to have been disarmed by a lack of confidence in 


\begin{tabular}{lll}
\hline & Third-year Students & Lecturers \\
\hline Applied Knowledge & $\begin{array}{l}\text { Useful for other modules } \\
\text { Useful for placements } \\
\text { Can be used in assignments }\end{array}$ & $\begin{array}{l}\text { Useful for multi-disciplinary teaching } \\
\text { Useful for placement preparation }\end{array}$ \\
\hline Self-directed learning & $\begin{array}{l}\text { Leam in own time and learn } \\
\text { at own pace } \\
\text { Encourage self-directed study } \\
\text { Makes learning interesting } \\
\text { Saves you wading through books }\end{array}$ & $\begin{array}{l}\text { Students still need to do their own research } \\
\text { Would be disappointed if students did not } \\
\text { look further } \\
\text { Weaker students may not look further } \\
\text { findings with others } \\
\text { Students' thinking may be limited by the } \\
\text { linking }\end{array}$ \\
\end{tabular}

Table 3: Example comments regarding the perceived advantages and disadvantages of using the CAT Microcosm application

their individual knowledge and experience. This perhaps suggests that the discussion excluded those who for whatever reason did not feel 'qualified' to join in the discussion (see Table 3).

\section{Disarmed by restrictions on self-directed learning}

For the CAT Microcosm application, analysis of responses to open questions revealed disagreements between students and lecturers regarding self-directed leaming. Students felt the package would encourage self-directed learning because users can learn in their own time and pace. While lecturers expressed concern that students' thinking may be limited by the linking within the package and some students might not look further than the CAT resource base and thus may not be as self-directed as they perhaps could be (see Table 3).

\section{Discussion}

For the email discussion list the results reveal that a lack of confidence and a low valuation of the discussion could disarm users. Possible reasons why students felt unconfident may relate to the way the email list was set up. For example, the membership of the group was quite large (over 70) and there was no anonymity when posting messages to the list. These two things combined may have served to exclude those students who were afraid of exhibiting their 'ignorance' in such a public arena. These problems could be solved with a bit more creative thinking on behalf of the list owner.

The apparent low valuation of the email discussion list may be explained by examining the role of the list owner. Both Laurillard (1993) and McLoughlin and Oliver (1998) consider that the - tutor plays a pivotal role in encouraging conversation and reflection. They suggest strategies for achieving such a role that include clarifying expectations, promoting verbal expressions of different perspectives and encouraging alternative solutions or approaches. Perhaps the owner of the email discussion list failed to engage her students in an open dialogue about the objectives for using the email list and therefore there was no negotiation about the process or goals of learning.

For the CAT Microcosm application the results reveal that users may be disarmed by a perceived restriction that the application places on self-directed learning. A possible reason why 
the application may be seen to place restrictions on self-directed learning is the fact that it is a self-contained resource base. Given that students are expected to search the resource base to find out more information about their chosen case study they may be given the impression that all the answers are held within the resource base. If all the answers were held within such an expert system there would seem to be no reason to direct learning to other sources of information. Solutions to this disarmament problem may involve revisiting the design of the CAT application and perhaps changing the links within the application so that students are encouraged to take paths out of the self-contained resource base. Alternatively, the author of the package may need to make explicit to the students her leaming goals and so for example 'sell' the package as the springboard to other sources of knowledge.

\section{Implications for lifelong learning}

In the introduction an argument was made that focused on the idea that learning technologies can play a role in converting learners to a culture of critical thinking and reflection as opposed to a culture of knowledge acquisition. The two case examples described in this paper have served to illustrate how learning technologies can help students to acquire information and knowledge. However, it is debatable whether the use of these learning technologies has helped to produce lifelong leamers that are capable of critical thinking and reflection. The way these technologies were used means that neither did particularly well in promoting such skills as discussion or self-directed learning. These skills would seem to be essential if students are to fulfil their potential and improve themselves.

The two case studies described in this paper are preliminary investigations, which gathered information from only a small number of students. Whilst the results from the two case studies suggest that the use of learning technologies may place obstacles in the way of lifelong learning, more detailed work needs to be undertaken in order to test the conclusion drawn here that learners will be disarmed unless educators are creative in their design and use of learning technologies and enterprising in how they negotiate and promote the objectives for using learning technologies with students.

\section{References}

Blunkett, D. (1998), Foreword to The Learning Age: A Renaissance for a New Britain, Government Green Paper.

Carswell, L. (1998), 'Possible versus desirable in instructional systems: who's driving?' ALT-J, $6,1,70-80$.

Grabinger, S., Dunlap, J. C. and Duffield, J. A. (1997), 'Rich environments for active learning in action: problem-based learning', ALT-J, 5 (2), 5-17.

Hammond, N. and Tripp, A. (1992), 'CAL as a Trojan Horse for educational change: the case of psychology', Computers and Education, 19 (1/2), 87-95.

Khan, T. and Yip, Y. J. (1996), 'Pedagogic principles of case-based CAL', Journal of Computer Assisted Learning, 12, 172-92.

Laurillard, D. (1993), Rethinking University Teaching: A Framework for the Effective Use of Educational Technology, London: Routledge. 
Lovie, F., McLean, A. and Newlands, D. (1996), 'Access through technology: a comparison between conventional and distance learning students', Active Learning, 5, 30-5.

McAteer, E., Tolmie, A., Duffy, C. and Corbett, J. (1997), 'Computer-mediated communication as a learning resource', Journal of Computer Assisted Learning, 13, 219-27.

McLoughlin, C. and Oliver, R. (1998), 'Maximising the language and learning link in computer learning environments', British Journal of Educational Technology, 29 (2), 125-36.

Porritt, N. (1997), 'Managing to learn with technology', Active Learning, 7, 17-28.

Seale, J. (1997), 'Computer applications in therapy: evaluation of a multimedia teaching package', in Sinclair, K., Wing Fu, C. and King, B. (eds.), Proceedings of the Hong Kong International Occupational Therapy Congress, Hong Kong Polytechnic University.

Steeples, C., Unsworth, C., Bryson, M., Goodyear, P., Riding, P., Fowell, S., Levey, P. and Duffy, C. (1996), 'Technological support for teaching and learning: computer-mediated communication in higher education (CMC in HE)', Computers and Education, 26 (1-3), 71-80. 